\title{
Genetic Polymorphisms Contribute to the Individual Variations of Imatinib Mesylate Plasma Levels and Adverse Reactions in Chinese GIST Patients
}

\author{
Jing Liu ${ }^{1,+}{ }^{+}$, Zhiyu Chen ${ }^{2,+}{ }^{+}$Hanmei Chen ${ }^{1}$, Yingyong Hou ${ }^{3}$, Weiqi Lu ${ }^{4}$, Junyi He ${ }^{4}$, \\ Hanxing Tong ${ }^{4}$, Yuhong Zhou ${ }^{5, *}$ and Weimin Cai ${ }^{1, *}$ \\ 1 Department of Clinical Pharmacy, School of Pharmacy, Fudan University, Shanghai 201203, China; \\ nihaoliujing_001@126.com (J.L.); 14211030047@fudan.edu.cn (H.C.) \\ 2 Department of Medical Oncology, Shanghai Cancer Center, Fudan University, Shanghai 200032, China; \\ chanhj75@aliyun.com \\ 3 Department of Pathology, Zhongshan Hospital, Fudan University, Shanghai 200032, China; \\ hou.yingyong@zs-hospital.sh.cn \\ 4 Department of General Surgery, Zhongshan Hospital, Fudan University, Shanghai 200032, China; \\ lu.weiqi@zs-hospital.sh.cn (W.L.); doctorhjy@163.com (J.H.); thx121@163.com (H.T.) \\ 5 Department of Medical Oncology, Zhongshan Hospital, Fudan University, Shanghai 200032, China \\ * Correspondence: zhou.yuhong@zs-hospital.sh.cn (Y.Z.); weimincai@fudan.edu.cn (W.C.); \\ Tel.: +86-139-1828-6810 (Y.Z.); +86-21-5198-0023 (W.C.) \\ + These authors contributed equally to this work.
}

Academic Editor: William Chi-shing Cho

Received: 31 December 2016; Accepted: 4 March 2017; Published: 13 March 2017

\begin{abstract}
Imatinib mesylate (IM) has dramatically improved the outcomes of gastrointestinal stromal tumor (GIST) patients. However, the clinical responses of IM may considerably vary among single individuals. This study aimed to investigate the influences of genetic polymorphisms of drug-metabolizing enzyme (CYP3A4), transporters (ABCB1, ABCG2), and nuclear receptor (Pregnane $\mathrm{X}$ Receptor (PXR, encoded by NR1I2)) on IM plasma levels and related adverse reactions in Chinese GIST patients. A total of 68 Chinese GIST patients who have received IM 300-600 mg/day were genotyped for six single nucleotide polymorphisms (SNPs) (CYP3A4 rs2242480; ABCB1 rs1045642; ABCG2 rs2231137; NRI12 rs3814055, rs6785049, rs2276706), and the steady-state IM trough plasma concentrations were measured by a validated HPLC method. There were statistically significant variances in the steady-state IM trough plasma concentrations (from 272.22 to $4365.96 \mathrm{ng} / \mathrm{mL}$ ). Subjects of GG in $r s 2242480, T$ allele carriers in $r s 1045642$ and CC in $r s 3814055$ had significantly higher steady-state IM dose-adjusted trough plasma concentrations. Subjects of CC in rs3814055 had significantly higher incidence rate of edema. The genetic polymorphisms of $r s 2242480, r s 1045642$, rs3814055 were significantly associated with IM plasma levels, and the genetic variations of $r s 3814055$ were significantly associated with the incidence rate of edema in Chinese GIST patients. The current results may serve as valuable fundamental knowledge for IM therapy in Chinese GIST patients.
\end{abstract}

Keywords: imatinib mesylate; gastrointestinal stromal tumor; genetic polymorphisms; plasma levels; adverse reactions; Chinese

\section{Introduction}

Gastrointestinal stromal tumors (GISTs) are epidemiologically analyzed to be the most common form of the mesenchymal tumor of the gastrointestinal tract, as the worldwide incidence and prevalence are estimated to be approximately 1 to 1.5 per 100,000 per year and 13 per 100,000, respectively [1]. At the present time, the combined application of surgery resection and molecular targeted drugs 
therapy is the most effective treatment for patients with the middle or high risk GISTs. Imatinib mesylate (IM) is a first-line targeted therapy for inoperable, metastatic, or recurrent KIT-positive GIST and for the adjuvant treatment of patients following resection of primary KIT-positive GIST [2]. After the clinical introduction of IM, the patient outcomes for GIST have been dramatically improved, with an impressive impact on both quality of life and long-term prognosis. However, there are large individual variations in clinical efficacy and adverse reactions of IM [3-5]. Ten to fifteen percent of patients who underwent IM treatment after 3-6 months progressed rapidly to widespread metastatic disease [6], about $30 \%$ of patients who developed serious adverse reactions had to stop taking medication [7]. Recently, the relationship between IM plasma concentrations and efficacy and toxicity have been described [8,9], minimal plasma concentration thresholds (1100 ng/mL) have been established, under which a substantial increase in treatment failure and drug resistance was observed [10]. Thus, inter-individual variations in IM pharmacokinetics may, therefore, have important clinical consequences. This implicates that timely monitoring of IM plasma concentration is warranted in GIST patients.

It has been found that genetic polymorphisms of main drug-metabolizing enzymes and transporters may significantly influence the inter-individual variations in drug reaction and disposition [11]. IM is orally administrated and was mainly metabolized in the liver by cytochrome P450 3A4 (CYP3A4), and effluxed by ATP Binding Cassette Subfamily B Member 1 (ABCB1, P-glycoprotein), ATP Binding Cassette Subfamily G Member 2 (ABCG2, BCRP), etc. The current studies of individualized therapy for IM mainly focused on the genetic polymorphisms of main drug-metabolizing enzymes (CYP3A4) [12] and transporters (ABCB1, ABCG2) [13,14]. However, the variant differences in IM clinical effects and adverse reactions remains controversial, suggesting that there are some other genetic factors neglected. In addition, CYP3A4 rs2242480, the highest frequency single nucleotide polymorphisms (SNPs) in the Chinese population [15] was found to be correlated with the increased activity of CYP3A4, indicating that it is likely to be associated with IM pharmacokinetics.

Recently, nuclear receptors, as domain transcriptional regulators, have been found to play a crucial role in regulating the expression of relevant drug metabolic enzymes and transporters. Pregnane $X$ Receptor (PXR, encoded by NR1I2), a member of the nuclear receptor superfamily, was increasingly found in simultaneously inducing the expression of CYP3A4 [16-19] and ABCB1 [17,18,20], predicting that the genetic polymorphisms of NRI12 may have an effect on IM pharmacokinetics.

Based on these observations, six SNPs (CYP3A4 rs2242480; ABCB1 rs1045642; ABCG2 rs2231137; NRI12 rs3814055, rs6785049, rs2276706), which have been associated with the expression and/or function of the above drug-metabolizing enzyme and transporters genes and/or proteins in IM pharmacokinetics pathway, and with the minor allele frequency higher than $10 \%$ in Asian, were chosen as candidate SNPs, in order to investigate the influence of CYP3A4, ABCB1, ABCG2 and NR1I2 genetic polymorphisms on the steady-state IM dose-adjusted trough plasma concentrations and related adverse reactions in Chinese GIST patients. The results can be served as valuable fundamental knowledge for IM therapy, in order to make the antitumor treatment more successfully, and increase the safety and long-term tolerability of IM in Chinese GIST patients.

\section{Results}

\subsection{Patients Characteristics and IM trough Plasma Concentrations}

Sixty-eight Chinese GIST patients were enrolled, including 39 males and 29 females, whose characteristics and biological values are shown in Table 1. There are significant differences in IM trough plasma concentrations, and the mean IM trough plasma concentration of the study population is $1134.30 \mathrm{ng} / \mathrm{mL}$, ranging from 272.22 to $4365.96 \mathrm{ng} / \mathrm{mL}$ (Table 2). About $47.06 \%$ of patients, whose IM trough plasma concentrations are under the minimal plasma concentration thresholds $(1100 \mathrm{ng} / \mathrm{mL})$, this may indicate a high risk of disease progression and treatment failure. 
Table 1. Characteristics and biological values of 68 Chinese GIST patients on the IM plasma concentration determination day.

\begin{tabular}{lc}
\hline Characters (Unit) & Mean \pm SD (Range) \\
\hline Patient characteristics & 68 \\
\hline Number of recipients & $56.11 \pm 0.50(29-78)$ \\
Age (years) & $39 / 29$ \\
Gender $($ male/female) & $166.00 \pm 7.04(150.00-182.00)$ \\
Height $(\mathrm{cm})$ & $61.51 \pm 9.47(45.00-85.00)$ \\
Weight $(\mathrm{kg})$ & $22.18 \pm 3.25(15.09-28.65)$ \\
BMI & \\
\hline Biological values & $5.37 \pm 1.42(2.01-12.40)$ \\
\hline White blood cell count $\left(\times 10^{9} / \mathrm{L}\right)$ & $3.70 \pm 0.51(2.42-5.10)$ \\
Red blood cell count $\left(\times 10^{12} / \mathrm{L}\right)$ & $3.19 \pm 1.30(0.50-11.50)$ \\
Neutrophil count $\left(\times 10^{9} / \mathrm{L}\right)$ & $117.83 \pm 12.00(46.00-152.00)$ \\
Hemoglobin $(\mathrm{g} / \mathrm{L})$ & $187.00 \pm 66.57(29.00-332.00)$ \\
Platelet $\left(\times 10^{9} / \mathrm{L}\right)$ & $30.17 \pm 11.28(5.00-73.00)$ \\
Alanine aminotransferase $(\mathrm{U} / \mathrm{L})$ & $31.67 \pm 4.75(12.80-77.00)$ \\
Aspartate aminotransferase $(\mathrm{U} / \mathrm{L})$ & $40.60 \pm 4.68(24.00-51.90)$ \\
Albumin $(\mathrm{g} / \mathrm{L})$ & $77.00 \pm 14.13(37.00-133.00)$ \\
Serum creatinine $(\mu \mathrm{mol} / \mathrm{L})$ & $227.80 \pm 71.55(96.00-512.00)$ \\
Uric acid $(\mu \mathrm{mol} / \mathrm{L})$ & $5.65 \pm 1.50(1.70-202.00)$ \\
Blood urea nitrogen $(\mathrm{mmol} / \mathrm{L})$ & \\
\hline
\end{tabular}

Abbreviations: GIST, Gastrointestinal stromal tumor; IM, Imatinib mesylate; BMI: Body Mass Index = Weight/ (Height/100) ${ }^{2}$; SD, Standard deviation.

Table 2. The steady-state IM trough plasma concentrations in 68 Chinese GIST patients.

\begin{tabular}{cc}
\hline Characters (Unit) & Mean \pm SD (Range) \\
\hline Number of total patients & 68 \\
IM trough plasma concentrations $(\mathrm{ng} / \mathrm{mL})$ & $1134.30 \pm 1141.69(272.22-4365.96)$ \\
Number of patients $(<1100 \mathrm{ng} / \mathrm{mL})$ & $3.71 \pm 2.53(0.68-10.91)$ \\
IM dose-adjusted trough plasma concentrations $(\mathrm{ng} / \mathrm{mL} / \mathrm{mg})$ & $32(47.06 \%)$ \\
IM trough plasma concentrations $(\mathrm{ng} / \mathrm{mL})$ & $713.86 \pm 239.76(272.22-1095.20)$ \\
IM dose-adjusted trough plasma concentrations $(\mathrm{ng} / \mathrm{mL} / \mathrm{mg})$ & $1.80 \pm 0.61(0.68-2.74)$ \\
Number of patients $(>1100 \mathrm{ng} / \mathrm{mL})$ & $36(52.94 \%)$ \\
IM trough plasma concentrations $(\mathrm{ng} / \mathrm{mL})$ & $2339.81 \pm 840.04(1118.31-4365.96)$ \\
IM dose-adjusted trough plasma concentrations $(\mathrm{ng} / \mathrm{mL} / \mathrm{mg})$ & $6.03 \pm 2.04(2.80-10.91)$ \\
\hline
\end{tabular}

Abbreviations: IM, Imatinib mesylate; GIST, Gastrointestinal stromal tumor; SD, Standard deviation.

\subsection{Genotype Frequencies}

Frequencies of the six SNPs' genotypes in the study population are shown in Table 3. The frequency expected for each genotype was evaluated on the basis of Hardy-Weinberg equilibrium. None of the observed SNPs' frequencies was significantly different from the expected frequencies $(p>0.05)$, illustrating that all of the six SNPs' frequencies in the study are in accordance with Hardy-Weinberg equilibrium. There is almost no linkage disequilibrium among all the six SNPs, and six SNPs in the study were in genetic equilibrium.

Comparisons of mutation frequencies for the six SNPs above, among different ethnic groups, are shown in Table 4. None of the observed SNPs' frequencies in the study population were significantly different from the Healthy Han Chinese and Asian, but all six SNPs' mutation frequencies were significantly different from Caucasian and African. These SNPs may contribute to inter-individual variations of IM reaction and disposition among different ethnic groups. 
Table 3. Frequencies of six SNPs in 68 Chinese GIST patients.

\begin{tabular}{|c|c|c|c|c|c|c|c|}
\hline SNP_ID & Gene & Genotype & $n$ & $\begin{array}{c}\text { Identified } \\
\text { Frequency (\%) }\end{array}$ & Allele & $\begin{array}{c}\text { Allele } \\
\text { Frequency (\%) }\end{array}$ & $\begin{array}{c}\text { HWE } \\
p \text {-Value }\end{array}$ \\
\hline \multirow{3}{*}{ rs 2242480} & \multirow{3}{*}{ СУР $3 A 4$} & $G G$ & 48 & 70.59 & $G$ & 82.35 & \multirow{3}{*}{0.12} \\
\hline & & $G A$ & 16 & 23.53 & $A$ & 17.65 & \\
\hline & & $A A$ & 4 & 5.88 & & & \\
\hline \multirow{3}{*}{ rs1045642 } & \multirow{3}{*}{$A B C B 1$} & $C C$ & 29 & 42.64 & $C$ & 63.24 & \multirow{3}{*}{0.52} \\
\hline & & $C T$ & 28 & 41.18 & $T$ & 36.76 & \\
\hline & & TT & 11 & 16.18 & & & \\
\hline \multirow{3}{*}{ rs 2231137} & \multirow{3}{*}{ ABCG2 } & GG & 28 & 41.18 & $G$ & 63.97 & \multirow{3}{*}{0.99} \\
\hline & & $G A$ & 31 & 45.59 & $A$ & 36.03 & \\
\hline & & $A A$ & 9 & 13.23 & & & \\
\hline \multirow{3}{*}{ rs3814055 } & \multirow{3}{*}{ NR1I2 } & $C C$ & 41 & 60.30 & $C$ & 76.47 & \multirow{3}{*}{0.60} \\
\hline & & CT & 22 & 32.35 & $T$ & 23.53 & \\
\hline & & $\mathrm{TT}$ & 5 & 7.35 & & & \\
\hline \multirow{3}{*}{ rs6785049 } & \multirow{3}{*}{ NR1I2 } & $G G$ & 21 & 30.88 & $G$ & 55.88 & \multirow{3}{*}{0.99} \\
\hline & & GA & 34 & 50.00 & $A$ & 44.12 & \\
\hline & & $A A$ & 13 & 19.12 & & & \\
\hline \multirow{3}{*}{ rs2276706 } & \multirow{3}{*}{ NR1I2 } & $G G$ & 39 & 57.35 & $G$ & 75.00 & \multirow{3}{*}{0.84} \\
\hline & & $G A$ & 24 & 35.30 & $A$ & 25.00 & \\
\hline & & $A A$ & 5 & 7.35 & & & \\
\hline
\end{tabular}

Abbreviations: SNPs, single nucleotide polymorphisms; GIST, Gastrointestinal stromal tumor; $n$, the numbers of patients; HWE, Hardy-Weinberg equilibrium.

\subsection{Effect of Genetic Polymorphisms of Drug-Metabolizing Enzyme CYP3A4 on IM Plasma Levels}

For CYP3A4 rs2242480, the steady-state IM dose-adjusted trough plasma concentrations in mutant allele $A$ carriers $(G A+A A)(2.27 \pm 0.32 \mathrm{ng} / \mathrm{mL} / \mathrm{mg})$ were significantly lower than that in wild-types $(G G)(4.12 \pm 0.40 \mathrm{mg} / \mathrm{mL} / \mathrm{mg})(p=0.0171)$ (Figure 1, Table 5).

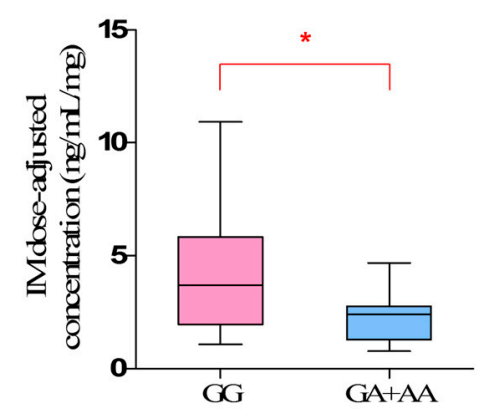

CYP3A4 rs2242480 genotypes

Figure 1. The steady-state Imatinib mesylate (IM) dose-adjusted trough plasma concentrations related to CYP3A4 rs2242480 genotypes in 68 Chinese gastrointestinal stromal tumor (GIST) patients. $\left({ }^{*} p<0.05\right)$. 
Table 4. Comparisons of mutation frequencies for six SNPs among different ethnic groups.

\begin{tabular}{|c|c|c|c|c|c|c|c|c|c|c|c|c|c|c|}
\hline \multirow{3}{*}{ SNP } & \multicolumn{14}{|c|}{ Mutation Frequency (\%) } \\
\hline & \multicolumn{2}{|c|}{ Study Population } & \multicolumn{3}{|c|}{ Healthy Han Chinese } & \multicolumn{3}{|c|}{ Asian } & \multicolumn{3}{|c|}{ Caucasian } & \multicolumn{3}{|c|}{ African } \\
\hline & $n$ & Freq. $^{a}$ & $n$ & Freq. $^{a}$ & Ref. $^{b}$ & $n$ & Freq. $^{a}$ & Ref. $^{b}$ & $n$ & Freq. ${ }^{a}$ & Ref. $^{b}$ & $n$ & Freq. $^{a}$ & Ref. $^{b}$ \\
\hline$r s 2242480$ & 68 & 17.68 & 976 & 22.10 & [15] & 120 & 20.00 & NCBI & 218 & $7.34^{* *}$ & NCBI & 224 & $85.71^{\mathrm{c}, * *}$ & NCBI \\
\hline rs1045642 & 68 & 36.76 & 208 & 40.40 & [21] & 120 & 43.33 & NCBI & 226 & $51.79 * *$ & NCBI & 226 & $11.06^{c, * *}$ & NCBI \\
\hline rs 2231137 & 68 & 36.03 & 90 & 28.89 & NCBI & 120 & 29.55 & NCBI & 120 & $1.67^{* *}$ & NCBI & 120 & $5.00^{e, * *}$ & NCBI \\
\hline rs3814055 & 68 & 23.53 & 286 & 21.80 & {$[22]$} & 120 & 22.50 & NCBI & 226 & $36.58^{* *}$ & NCBI & 226 & $30.64^{d}$ & NCBI \\
\hline rs6785049 & 68 & 44.12 & 300 & 37.00 & [22] & 172 & 51.67 & NCBI & 226 & $62.33 * *$ & NCBI & 226 & $3.56^{* *}$ & NCBI \\
\hline$r s 2276706$ & 68 & 25.00 & 286 & 21.80 & [22] & 120 & 22.50 & NCBI & 120 & $40.00 * *$ & NCBI & 116 & $27.59^{c}$ & NCBI \\
\hline
\end{tabular}

${ }^{a}$ Frequency; ${ }^{\mathrm{b}}$ Reference; ${ }^{\mathrm{c}}$ Sub-Saharan African; ${ }^{\mathrm{d}}$ African-American; ${ }^{\mathrm{e}}$ Yoruba in Ibadan; ${ }^{* *} p<0.01$. Abbreviations: SNPs, single nucleotide polymorphisms; $n$, the numbers of patients. 
Table 5. Association of CYP3A4 rs2242480 genotypes with the steady-state IM dose-adjusted concentrations in 68 Chinese GIST patients.

\begin{tabular}{|c|c|c|c|c|c|}
\hline \multirow{2}{*}{ SNP_ID } & \multirow{2}{*}{ Gene } & \multirow{2}{*}{ Genotype } & \multirow{2}{*}{$n$} & \multicolumn{2}{|c|}{ IM Dose-Adjusted Concentration (ng/mL/mg) } \\
\hline & & & & Mean \pm SD & $p$ \\
\hline rs2242480 & CYP3A4 & $\begin{array}{c}G G \\
G A+A A\end{array}$ & $\begin{array}{l}48 \\
20\end{array}$ & $\begin{array}{l}4.12 \pm 0.40 \\
2.27 \pm 0.32\end{array}$ & $0.0171 *$ \\
\hline
\end{tabular}

Abbreviations: IM, Imatinib mesylate; GIST, Gastrointestinal stromal tumor; SNP, Single nucleotide polymorphism; $n$, the numbers of patients; SD, Standard deviation. ${ }^{*} p<0.05$.

\subsection{Effect of Genetic Polymorphisms of Transporters ABCB1/ABCG2 on IM Plasma Levels}

For $A B C B 1$ rs1045642, the steady-state IM dose-adjusted trough plasma concentrations in mutant allele $T$ carriers $(C T+T T)(4.36 \pm 0.45 \mathrm{ng} / \mathrm{mL} / \mathrm{mg})$ were significantly higher than that in wild-types (CC) $(2.56 \pm 0.33 \mathrm{mg} / \mathrm{mL} / \mathrm{mg})(p=0.0055)$ (Figure 2a, Table 6).

For $A B C G 2$ rs2231137, there is no significant difference in the mean steady-state IM dose-adjusted trough plasma concentration in observed genotypes $(p>0.05)$ (Figure $2 b$, Table 6$)$.

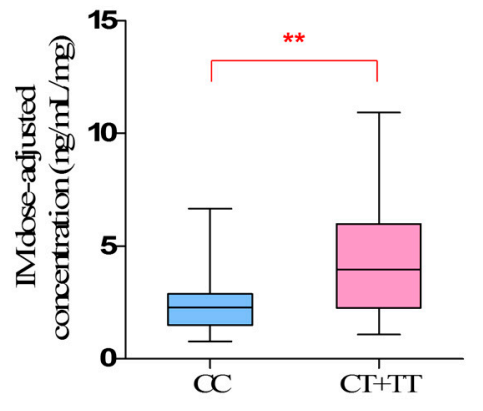

ABCBI rs 1045642 genotypes

(a)

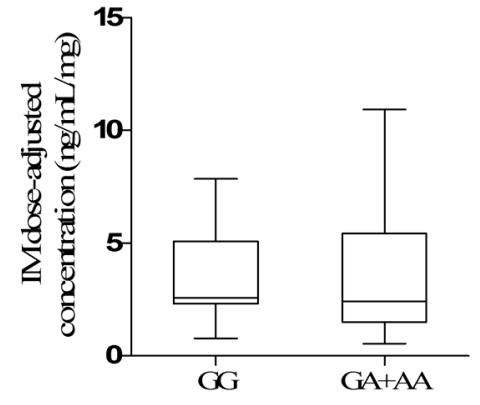

$A B C G 2$ rs2231137 genotypes

(b)

Figure 2. The steady-state Imatinib mesylate (IM) dose-adjusted trough plasma concentrations related to $A B C B 1$ rs1045642 (a) and ABCG2 rs2231137 (b) genotypes in 68 Chinese gastrointestinal stromal tumor (GIST) patients $(* * p<0.01)$.

Table 6. Association of $A B C B 1 / A B C G 2$ polymorphisms with the steady-state IM dose-adjusted concentrations in 68 Chinese GIST patients.

\begin{tabular}{|c|c|c|c|c|c|}
\hline \multirow{2}{*}{ SNP_ID } & \multirow{2}{*}{ Gene } & \multirow{2}{*}{ Genotype } & \multirow{2}{*}{$n$} & \multicolumn{2}{|c|}{ IM Dose-Adjusted Concentration (ng/mL/mg) } \\
\hline & & & & Mean \pm SD & $p$ \\
\hline \multirow{2}{*}{ rs1045642 } & \multirow[b]{2}{*}{$A B C B 1$} & CC & 29 & $2.56 \pm 0.33$ & \multirow[b]{2}{*}{$0.0055^{* *}$} \\
\hline & & $C T+T T$ & 39 & $4.36 \pm 0.45$ & \\
\hline \multirow{2}{*}{ rs2231137 } & \multirow{2}{*}{ ABCG2 } & GG & 28 & $3.51 \pm 0.40$ & \multirow{2}{*}{0.7158} \\
\hline & & $G A+A A$ & 40 & $3.76 \pm 0.50$ & \\
\hline
\end{tabular}

Abbreviations: IM, Imatinib mesylate; GIST, Gastrointestinal stromal tumor; SNP, Single nucleotide polymorphism; $n$, the numbers of patients; SD, Standard deviation. ${ }^{* *} p<0.01$.

\subsection{Effect of Genetic Polymorphisms of Nuclear Receptor PXR on IM Plasma Levels}

For NR1I2 rs3814055, the steady-state IM dose-adjusted trough plasma concentrations in mutate allele $T$ carriers $(C T+T T)(2.34 \pm 0.25 \mathrm{ng} / \mathrm{mL} / \mathrm{mg})$ were significantly lower than that in wild-types (CC) $(4.26 \pm 0.43 \mathrm{mg} / \mathrm{mL} / \mathrm{mg})(p=0.0066)$ (Figure 3a, Table 7).

For NR1I2 rs6785049 and $r s 2276706$, there is no significant difference in the mean steady-state IM dose-adjusted trough plasma concentrations in observed genotypes $(p>0.05)$. (Figure $3 b, c$ and Table 7$)$. 


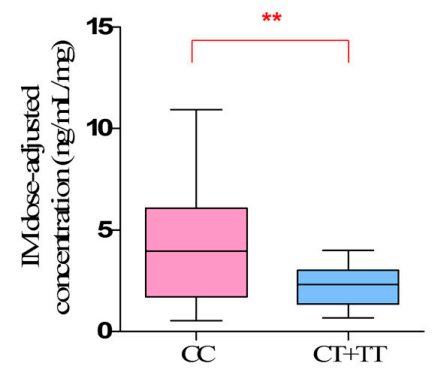

NRII2 rs3814055 genotpyes

(a)

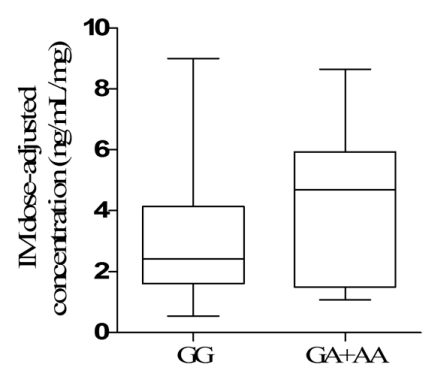

NRII2 rs6785049 genotpyes

(b)

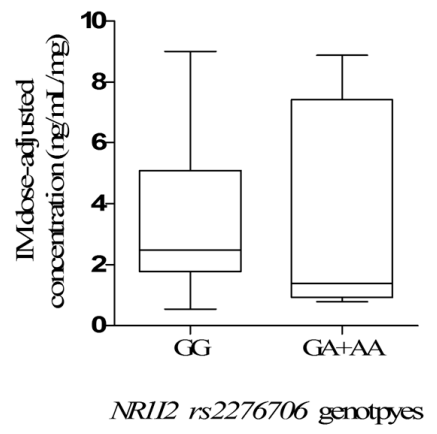

(c)

Figure 3. The steady-state Imatinib mesylate (IM) dose-adjusted trough plasma concentrations related to NR1I2 rs3814055 (a); rs6785049 (b); and rs2276706 (c) genotypes in 68 Chinese gastrointestinal stromal tumor (GIST) patients $\left({ }^{* *} p<0.01\right)$.

Table 7. Association of NR1I2 polymorphisms with the steady-state IM dose-adjusted concentrations in 68 Chinese GIST patients.

\begin{tabular}{|c|c|c|c|c|c|}
\hline \multirow{2}{*}{ SNP_ID } & \multirow{2}{*}{ Gene } & \multirow{2}{*}{ Genotype } & \multirow{2}{*}{$n$} & \multicolumn{2}{|c|}{ IM Dose-Adjusted Concentration (ng/mL/mg) } \\
\hline & & & & Mean \pm SD & $p$ \\
\hline \multirow{2}{*}{ rs3814055 } & \multirow{2}{*}{ NR1I2 } & CC & 41 & $4.26 \pm 0.43$ & \multirow{2}{*}{$0.0066^{* *}$} \\
\hline & & $C T+T T$ & 27 & $2.34 \pm 0.25$ & \\
\hline \multirow{2}{*}{ rs6785049 } & \multirow{2}{*}{ NR1I2 } & GG & 21 & $3.17 \pm 0.33$ & \multirow{2}{*}{0.2010} \\
\hline & & $G A+A A$ & 47 & $4.09 \pm 0.73$ & \\
\hline \multirow{2}{*}{ rs 2276706} & \multirow{2}{*}{ NR1I2 } & GG & 39 & $3.55 \pm 0.32$ & \multirow{2}{*}{0.9556} \\
\hline & & $G A+A A$ & 29 & $3.62 \pm 1.62$ & \\
\hline
\end{tabular}

Abbreviations: IM, Imatinib mesylate; GIST, Gastrointestinal stromal tumor; SNP, Single nucleotide polymorphism; $n$, the numbers of patients; SD, Standard deviation. ${ }^{* *} p<0.01$.

\subsection{Effect of Genetic Polymorphisms on IM Adverse Reactions}

Among the 68 Chinese GIST patients, the most frequently observed adverse reactions related to IM include continuous edema, diarrhea, rash and myelosuppression.

For all six of the SNPs, only the mutation of NR1I2 rs3814055 was significantly associated with the incidence rate of continuous edema in the study population. The incidence rate of continuous edema in wild-types (CC) (34.15\%) in NR1I2 rs3814055 was significantly higher than that in mutate allele $T$ carriers $(C T+T T)(3.70 \%)(p=0.0030$, Odds ratio $(\mathrm{OR})=13.48,95 \%$ Confidence interval $(\mathrm{CI})$ : 1.65-109.98) (Figure 4, Table 8).

For the incidence rates of diarrhea, rash and myelosuppression, there are no significant differences in observed genotypes of all six SNPs $(p>0.05)$. 


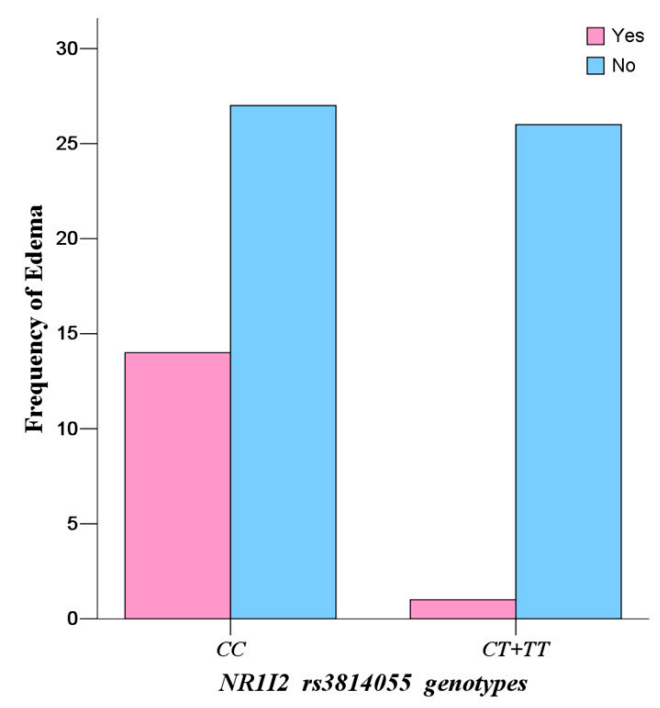

Figure 4. Comparison of the incidences of edema in 68 Chinese gastrointestinal stromal tumor (GIST) patients based on NR1I2 rs3814055 polymorphisms.

Table 8. Comparison of the incidences of edema related to NR1I2 rs3814055 polymorphisms in 68 Chinese GIST patients.

\begin{tabular}{|c|c|c|c|c|c|c|c|c|}
\hline \multirow{2}{*}{ SNP_ID } & \multirow{2}{*}{ Gene } & \multirow{2}{*}{ Genotype } & \multirow{2}{*}{$n$} & \multicolumn{5}{|c|}{ Edema } \\
\hline & & & & Yes (\%) & No $(\%)$ & $p$ & OR & $95 \% \mathrm{CI}$ \\
\hline rs3814055 & NR1I2 & $\begin{array}{c}C C \\
C T+T T\end{array}$ & $\begin{array}{l}41 \\
27\end{array}$ & $\begin{array}{c}14(34.15) \\
1(3.70)\end{array}$ & $\begin{array}{l}27(65.85) \\
26(96.30)\end{array}$ & $0.0030^{* *}$ & 13.48 & $\begin{array}{c}1.65 \\
109.98\end{array}$ \\
\hline
\end{tabular}

Abbreviations: GIST, Gastrointestinal stromal tumor; SNP, Single nucleotide polymorphism; $n$, the numbers of patients; OR, Odds ratio; CI, Confidence interval. ${ }^{* *} p<0.01$.

\section{Discussion}

In the past decade, imatinib mesylate, the first molecular-targeted drug with a known mechanism of efficacy, has radically changed the life expectancy of patients with GISTs. However, a large number of researchers have focused on the peculiar proto-oncogene of GISTs, and it can only partially explain the inter-individual variances of clinical response rate. While the germline DNA of patients remains important, as it dictates drug pharmacokinetics that may indirectly determine efficacy and toxicity. Based on these previous observations, we have involved the most relevant pharmacogenetic parameters, such as genetic polymorphisms of drug metabolizing enzymes, transporters and nuclear receptors, in order to investigate their influences on the steady-state IM dose-adjusted trough plasma concentrations and adverse reactions, for further explanation of the inter-individual variances on IM pharmacokinetics.

In our study, there was nearly a 16 -fold variance in the steady-state IM trough plasma concentrations (from 272.22 to $4365.96 \mathrm{ng} / \mathrm{mL}$ ) with IM doses ranging from 300 to $600 \mathrm{mg}$ daily, which is much larger than the previous reports [10,23]. In addition, $47.06 \%$ of patients in the study, whose IM trough plasma concentrations had not reached the predefined minimal plasma concentration thresholds $(1100 \mathrm{ng} / \mathrm{mL})$, may be at the higher risk of disease progression and treatment failure.

Our study clearly showed the clinical impact of CYP3A4 rs2242480 polymorphisms on IM plasma levels, and the steady-state IM dose-adjusted trough plasma concentrations in mutant allele $A$ carriers $(G A+A A)$ were significantly lower than that in wild-types $(G G)(p=0.0171)$. However, the influence of $r s 2242480$ polymorphisms on IM plasma levels in Chinese GIST patients has not been investigated previously. rs 2242480 , characterized by a G to A substitution in intron 10 of CYP3A4, is the most frequent SNP of CYP3A4 in the Chinese population. The frequency of mutant allele $A$ in the study was 
$17.58 \%$, similar to Healthy Han Chinese and Asian $[15,24]$, but significantly different from Caucasian (7.34\%) and African (85.71\%). The mutant allele $A$ was reported to be associated with a higher CYP3A4 metabolic activity [25-27], thus increasing the clearance of IM, which was mainly metabolized by CYP3A4, leading the lower IM plasma levels. Therefore, the mutant allele $A$ of $r s 2242480$ is a meaningful risk factor for predicting inadequate clinical efficacy of IM, and patients who carry mutant allele $A$ of $r s 2242480$ may be suggested to have a higher dose therapy.

In addition, our study obviously showed the clinical impact of $A B C B 1$ rs1045642 polymorphisms on IM plasma levels, and the steady-state IM dose-adjusted trough plasma concentrations in mutate allele $T$ carriers $(C T+T T)$ were significantly higher than that in wild-types $(C C)(p=0.0066)$. Interestingly, the same association has been reported in Chronic Myelogenous Leukemia (CML) [28] patients under IM treatment, corroborating the importance of IM pharmacokinetics. The frequency of mutant allele $T$ in the study was $36.76 \%$, similar to Healthy Han Chinese and Asian [21], but significantly different from Caucasian (51.79\%) and African (11.06\%). The ABCB1 rs1045642 mutant allele $T$ was reported to reduce the transcript levels of $A B C B 1$ mRNA in vivo by as much as two- to four-fold when compared with allele $C$ [29]. Thus, the mutant allele $T$ was associated with a lower production of P-glycoprotein, leading to a lower drug clearance capability [30,31]. This might be responsible for the observation in the study that the mutant allele $T$ carriers $(C T+T T)$ have the higher IM plasma levels. We suggest that the mutant allele $T$ of $r s 1045642$ is a significant risk factor for predicting excessive treatment of IM, and patients who carry the mutant allele $T$ of $r s 1045642$ may be suggested to have a lower dose therapy.

However, the most interesting finding is the influence of NR1I2 rs3814055 polymorphisms on IM plasma levels and adverse reaction. The steady-state IM dose-adjusted trough plasma concentrations in mutate allele $T$ carriers $(C T+T T)(2.34 \pm 0.25 \mathrm{ng} / \mathrm{mL} / \mathrm{mg})$ were significantly lower than that in wild-types (CC), and the incidence rate of edema in mutate allele $T$ carriers $(C T+T T)$ was significantly lower than that in wild-types $(C C)(p=0.0030, \mathrm{OR}=13.48,95 \%$ CI: $1.65-109.98)$. However, the influence of $r$ s3814055 polymorphisms on IM plasma levels and adverse reactions in Chinese GIST patients has not been reported previously, although a similar association has been reported in the studies on the pharmacokinetics of Tacrolimus in healthy subjects [32]. It is known that PXR is a crucial nuclear receptor to simultaneously regulate the expression of CYP3A4 [16-19] and ABCB1 [17,18,20]. rs3814055, located in $5^{\prime}$ Untranslated Regions of NRI12, is the highest frequency SNP of NR1I2 in the Chinese population. The frequency of mutant allele $T$ in the study was $23.53 \%$, similar to Healthy Han Chinese and Asian [22], but significantly different from Caucasian (36.58\%) and African (30.64\%). It is reported that the erythromycin breath test in mutant allele $T$ carriers $(C T+T T)$ was two times stronger than wild-types $(C C)$ by the inducing of rifampicin, indicated that mutant allele $T$ was associated with a higher transcript levels of CYP3A4 mRNA and metabolic activity $[33,34]$, thus increasing the clearance of IM, which was mainly metabolized by CYP3A4, leading to the lower IM plasma levels.

Continuous edema is the most common side effect of IM treatment, with incidence of $37.85 \%$ in the study population. Because severe and continuous edema (fluid retention) may result in interruption of IM, careful monitoring of severe edema is especially important in elderly patients (65 and older), patients with preexisting coronary artery disease or renal impairment and patients on higher doses of IM [35-37]. However, it is considered to be a concentration-dependent and dose-limiting adverse reaction of IM [38-40] — the higher the IM plasma concentrations, the higher the risk of incidence of the adverse reaction. This might be responsible for the observation in this study that the wild-types (CC) in NR1I2 rs3814055 have higher IM plasma levels, leading to a high incidence rate of continuous edema. Therefore, allele $C$ of $r s 3814055$ is a productive risk factor for predicting excessive treatment and high risk of adverse reaction of IM, and patients who carry the allele $C$ of $r s 3814055$ may be suggested to have a lower dose or adjuvant diuretic therapy. 


\section{Materials and Methods}

\subsection{Subjects and Study Design}

The study was performed according to the declaration of Helsinki and the International Conference on Harmonization-Good Clinical Practice standards. The study protocol was approved by the Ethics Committees of Zhongshan Hospital (ethical approval code: B2015-140R, 20151202) and the Shanghai Cancer Center (ethical approval code: 1604159-6, 20160425), affiliated with Fudan University. Details of the study were explained to all patients and informed consent was obtained. A total of 68 patients ( 39 males and 29 females) with newly diagnosed GIST were enrolled. All patients were orally administered 300-600 mg/day Imatinib Mesylate (Glivec, Novartis Pharma Stein AG, Basel, Switzerland) for at least one month. All of them were below 80 years of age, and had adequate hepatic and renal functions (Aspartate aminotransferase (AST)/ Alanine aminotransferase $($ ALT) $<2 \times$ upper limit of normal (ULN), Total bilirubin in serum (TBIL) $<1.25 \times$ ULN, Serum creatinine $(\mathrm{Scr})<1.5 \times \mathrm{ULN})$. Patients who received medication known to affect IM plasma levels, such as verapamil, ketoconazole, and itraconazole, were excluded.

When IM plasma concentration reached a steady state (IM was regularly taken for 1 month at least), peripheral blood samples ( $0.5 \mathrm{~h}$ before IM dosing) of each GIST patient were drawn for IM trough plasma concentration determination and genotyping analysis, and the characteristics and biological values of the study population were recorded and summarized on the same day.

\subsection{IM Trough Plasma Concentration Determination}

Within $1 \mathrm{~h}$ of peripheral blood sample collection, plasma samples were prepared by centrifuging at $4000 \times \mathrm{g}$ for $10 \mathrm{~min}$ at $4{ }^{\circ} \mathrm{C}$, and a $100 \mu \mathrm{L}$ aliquot of plasma was prepared by liquid-liquid extraction processing for IM trough plasma concentration determination, following a modified and validated HPLC method as reported earlier [41]. The HPLC system equipped with a Waters 1525 HPLC pump (Waters Corporation, Milford, MA, USA), a 2707 auto-sampler and a 2489 UV-detector linked to the Breeze $^{\mathrm{TM}}$ Chromatography Data processing workstation (Waters Corporation, Milford, MA, USA) for recording and storing throughout analysis. Reversed phase HPLC analysis was carried out using a Symmetry C18 column $(2.1 \mathrm{~mm} \times 150 \mathrm{~mm}, 3.5 \mu \mathrm{m})$ (Waters Corporation, Milford, MA, USA) maintained at ambient temperature, with a mobile phase of Acetonitrile- $20 \mathrm{mM}$ ammonium acetate buffer ( $\mathrm{pH}$ 6.8) $(30: 70, v / v)$, pumped at a flow rate of $0.2 \mathrm{~mL} / \mathrm{min}$ and $\mathrm{UV}$ detection at a wavelength of $265 \mathrm{~nm}$.

\subsection{DNA Extraction and Genotyping}

Total genomic DNA extraction was carried out using the method described previously [42]. The concentration and purity of extracted total genomic DNA samples were determined by a NANODROP LITE Spectrophotometer (Thermo Fisher Scientific Inc., Waltham, MA, USA). The genetic polymorphisms of CYP3A4 rs2242480, ABCB1 rs1045642, ABCG2 rs2231137 were determined by using polymerase chain reaction (PCR) restriction fragment length polymorphism (RFLP) method, while the genetic polymorphisms of NR1I2 rs3814055, rs6785049, rs2276706 were determined by using PCR and then sequencing. Analyses were performed using an Applied Biosysterms 2707 Thermal Cycler (Applied Biosystems, Foster, CA, USA). Sequencings were carried out on Thermo Fisher Scientific Inc. USA. Genotyping accuracy was confirmed by sequencing for two cases of each genotype. The PCR primers and reaction conditions were listed in the Supplementary Materials section (Tables S1-S3).

\subsection{Adverse Reactions Monitoring}

All patients were followed up in special clinics for GISTs to monitor IM-induced adverse reactions, which were evaluated according to the National Cancer Institute Common Terminology Criteria for Adverse Events version 4.0 (NCI CTCAE v4.0). 


\subsection{Statistical Analysis}

All statistical analyses were performed with SPSS ${ }^{\circledR}$ software, version 21.0 (IBM, Chicago, IL, USA). The results are expressed as mean $\pm \mathrm{SD}$, all of the tests were two-sided, and two-sided $p<0.05$ was considered as statistically significant.

The Hardy-Weinberg equilibrium test was performed using an appropriate $\chi^{2}$-test. Linkage disequilibrium (LD) based association analysis was measured using the online software SHEsis (Bio-X Life Science Research Center, Shanghai, China) [43]. The statistical differences of IM dose-adjusted trough plasma concentration between genotypes of each SNP were analyzed by Mann-Whitney or Kruskal-Wallis tests. The statistical differences of IM adverse reactions between genotypes of each SNP were analyzed by chi-square or Fisher's exact tests.

\section{Conclusions}

In summary, our findings indicate that the genetic polymorphisms of CYP3A4, ABCB1 and NR1I2 may make an important contribution to IM plasma levels and related adverse reactions. Because of the limited sample size of the study, further research should be carried out to verify the associated genetic polymorphisms on IM plasma levels and adverse reactions. The current results may serve as valuable fundamental knowledge for IM therapy in Chinese GIST patients.

Supplementary Materials: Supplementary materials can be found at www.mdpi.com/1422-0067/18/3/603/s1.

Acknowledgments: Our work was supported by the Shanghai Municipal Commission of Health and Family Planning, key development discipline (No. 2015ZB0201), and the Shanghai Municipal Science and Technology Commission (13411950802 and 14411970000).

Author Contributions: Jing Liu, Weimin Cai, and Yuhong Zhou conceived and designed the experiments; Jing Liu and Hanmei Chen performed the experiments; Jing Liu and Zhiyu Chen analyzed the data; Yingyong Hou, Weiqi Lu, Junyi He and Hanxing Tong helped to enroll and monitor the patients; and Jing Liu, Weinmin Cai and Yuhong Zhou wrote the paper.

Conflicts of Interest: The authors declare no conflict of interest.

\section{Abbreviations}

$\begin{array}{ll}\text { ABCB1 } & \text { ATP-binding cassette (ABC) transporters subfamily B member } 1 \\ \text { ABCG2 } & \text { ATP-binding cassette (ABC) transporters subfamily G member } 2 \\ \text { ALT } & \text { Alanine aminotransferase } \\ \text { AST } & \text { Aspartate aminotransferase } \\ \text { CI } & \text { Confidence interval } \\ \text { CYP3A4 } & \text { Cytochrome P450 3A4 } \\ \text { GIST } & \text { Gastrointestinal stromal tumor } \\ \text { HPLC } & \text { High Performance Liquid Chromatography } \\ \text { HWE } & \text { Hardy-Weinberg equilibrium } \\ \text { IM } & \text { Imatinib mesylate } \\ \text { OR } & \text { Odds ratio } \\ \text { PCR } & \text { Polymerase chain reaction } \\ \text { PXR } & \text { Pregnane X Receptor } \\ \text { RFLP } & \text { Restriction fragment length polymorphism } \\ \text { Scr } & \text { Serum creatinine } \\ \text { SNP } & \text { Single nucleotide polymorphism } \\ \text { TBIL } & \text { Total bilirubin in serum } \\ \text { ULN } & \text { Upper limit of normal }\end{array}$

\section{References}

1. Inayat, F.; Saif, M.W. New Drug and Possible New Toxicity-Squamous Cell Carcinoma Following Imatinib in Patients with Gastrointestinal Stromal Tumors. Anticancer Res. 2016, 36, 6201-6204. [CrossRef] [PubMed]

2. Nishida, T.; Blay, J.Y.; Hirota, S.; Kitagawa, Y.; Kang, Y.K. The standard diagnosis, treatment, and follow-up of gastrointestinal stromal tumors based on guidelines. Gastric Cancer 2016, 19, 3-14. [CrossRef] [PubMed] 
3. Gao, B.; Yeap, S.; Clements, A.; Balakrishnar, B.; Wong, M.; Gurney, H. Evidence for therapeutic drug monitoring of targeted anticancer therapies. J. Clin. Oncol. 2012, 30, 4017-4025. [CrossRef] [PubMed]

4. Klumpen, H.J.; Samer, C.F.; Mathijssen, R.H.; Schellens, J.H.; Gurney, H. Moving towards dose individualization of tyrosine kinase inhibitors. Cancer Treat. Rev. 2011, 37, 251-260. [CrossRef] [PubMed]

5. Slaviero, K.A.; Clarke, S.J.; Rivory, L.P. Inflammatory response: An unrecognised source of variability in the pharmacokinetics and pharmacodynamics of cancer chemotherapy. Lancet Oncol. 2003, 4, 224-232. [CrossRef]

6. Demetri, G.D.; von Mehren, M.; Blanke, C.D.; van den Abbeele, A.D.; Eisenberg, B.; Roberts, P.J.; Heinrich, M.C.; Tuveson, D.A.; Singer, S.; Janicek, M.; et al. Efficacy and safety of imatinib mesylate in advanced gastrointestinal stromal tumors. N. Engl. J. Med. 2002, 347, 472-480. [CrossRef] [PubMed]

7. Dematteo, R.P.; Ballman, K.V.; Antonescu, C.R.; Maki, R.G.; Pisters, P.W.; Demetri, G.D.; Blackstein, M.E.; Blanke, C.D.; von Mehren, M.; Brennan, M.F.; et al. Adjuvant imatinib mesylate after resection of localised, primary gastrointestinal stromal tumour: A randomised, double-blind, placebo-controlled trial. Lancet 2009, 373, 1097-1104. [CrossRef]

8. Delbaldo, C.; Chatelut, E.; Ré, M.; Deroussent, A.; Séronie-Vivien, S.; Jambu, A.; Berthaud, P.; Le Cesne, A.; Blay, J.Y.; Vassal, G. Pharmacokinetic-pharmacodynamic relationships of imatinib and its main metabolite in patients with advanced gastrointestinal stromal tumors. Clin. Cancer Res. 2006, 12, 6073-6078. [CrossRef] [PubMed]

9. Widmer, N.; Decosterd, L.A.; Leyvraz, S.; Duchosal, M.A.; Rosselet, A.; Debiec-Rychter, M.; Csajka, C.; Biollaz, J.; Buclin, T. Relationship of imatinib-free plasma levels and target genotype with efficacy and tolerability. Br. J. Cancer 2008, 98, 1633-1640. [CrossRef] [PubMed]

10. Demetri, G.D.; Wang, Y.; Wehrle, E.; Racine, A.; Nikolova, Z.; Blanke, C.D.; Joensuu, H.; von Mehren, M. Imatinib plasma levels are correlated with clinical benefit in patients with unresectable/metastatic gastrointestinal stromal tumors. J. Clin. Oncol. 2009, 27, 3141-3147. [CrossRef] [PubMed]

11. Evans, W.E.; McLeod, H.L. Pharmacogenomics-Drug disposition, drug targets, and side effects. N. Engl. J. Med. 2003, 348, 538-549. [PubMed]

12. O’Brien, K.M.; Orlow, I.; Antonescu, C.R.; Ballman, K.; McCall, L.; DeMatteo, R.; Engel, L.S. Gastrointestinal stromal tumors, somatic mutations and candidate genetic risk variants. PLoS ONE 2013, 8, e62119. [CrossRef] [PubMed]

13. Koo, D.H.; Ryu, M.H.; Ryoo, B.Y.; Beck, M.Y.; Na, Y.S.; Shin, J.G.; Lee, S.S.; Kim, E.Y.; Kang, Y.K. Association of ABCG2 polymorphism with clinical efficacy of imatinib in patients with gastrointestinal stromal tumor. Cancer Chemother. Pharmacol. 2015, 75, 173-182. [CrossRef] [PubMed]

14. Eechoute, K.; Sparreboom, A.; Burger, H.; Franke, R.M.; Schiavon, G.; Verweij, J.; Loos, W.J.; Wiemer, E.A.; Mathijssen, R.H. Drug transporters and imatinib treatment: Implications for clinical practice. Clin. Cancer Res. 2011, 17, 406-415. [CrossRef] [PubMed]

15. Du, J.; Yu, L.; Wang, L.; Zhang, A.; Shu, A.; Xu, L.; Xu, M.; Shi, Y.; Li, X.; Feng, G.; et al. Differences in CYP3A41G genotype distribution and haplotypes of CYP3A4, CYP3A5 and CYP3A7 in 3 Chinese populations. Clin. Chim. Acta 2007, 383, 172-174. [CrossRef] [PubMed]

16. Xie, W.; Evans, R.M. Orphan nuclear receptors: The exotics of xenobiotics. J. Biol. Chem. 2001, 276, 37739-37742. [CrossRef] [PubMed]

17. Cerveny, L.; Svecova, L.; Anzenbacherova, E.; Vrzal, R.; Staud, F.; Dvorak, Z.; Ulrichova, J.; Anzenbacher, P. Valproic acid induces CYP3A4 and MDR1 gene expression by activation of constitutive androstane receptor and pregnane X receptor pathways. Drug Metab. Dispos. 2007, 35, 1032-1041. [CrossRef] [PubMed]

18. Burk, O.; Arnold, K.A.; Nussler, A.K.; Schaeffeler, E.; Efimova, E.; Avery, B.A.; Avery, M.A.; Fromm, M.F.; Eichelbaum, M. Antimalarial artemisinin drugs induce cytochrome P450 and MDR1 expression by activation of xenosensors pregnane X receptor and constitutive androstane receptor. Mol. Pharmacol. 2005, 67, 1954-1965. [CrossRef] [PubMed]

19. Burk, O.; Koch, I.; Raucy, J.; Hustert, E.; Eichelbaum, M.; Brockmöller, J.; Zanger, U.M.; Wojnowski, L. The induction of cytochrome P450 3A5 (CYP3A5) in the human liver and intestine is mediated by the xenobiotic sensors pregnane $X$ receptor (PXR) and constitutively activated receptor (CAR). J. Biol. Chem. 2004, 279, 38379-38385. [CrossRef] [PubMed] 
20. Albermann, N.; Schmitz-Winnenthal, F.H.; Z'graggen, K.; Volk, C.; Hoffmann, M.M.; Haefeli, W.E.; Weiss, J. Expression of the drug transporters MDR1/ABCB1, MRP1/ABCC1, MRP2/ABCC2, BCRP/ABCG2, and PXR in peripheral blood mononuclear cells and their relationship with the expression in intestine and liver. Biochem. Pharmacol. 2005, 70, 949-958. [CrossRef] [PubMed]

21. Li, D.; Zhang, G.L.; Lou, Y.Q.; Li, Q.; Wang, X.; Bu, X.Y. Genetic polymorphisms in MDR1 and CYP3A5 and MDR1 haplotype in mainland Chinese Han, Uygur and Kazakh ethnic groups. J. Clin. Pharm. Ther. 2007, 32, 89-95. [CrossRef] [PubMed]

22. Wang, X.D.; Li, J.L.; Su, Q.B.; Deng, X.Y.; Lu, Y.; Chen, J.; Zhang, J.X.; Zhao, L.Z.; Zuo, Z.; Chan, E.; et al. A pharmacogenetic study of pregnane $X$ receptor (NR1I2) in Han Chinese. Curr. Drug Metab. 2007, 8, 778-786. [CrossRef] [PubMed]

23. Yoo, C.; Ryu, M.H.; Kang, B.W.; Yoon, S.K.; Ryoo, B.Y.; Chang, H.M.; Lee, J.L.; Beck, M.Y.; Kim, T.W.; Kang, Y.K. Cross-sectional study of imatinib plasma trough levels in patients with advanced gastrointestinal stromal tumors: Impact of gastrointestinal resection on exposure to imatinib. J. Clin. Oncol. 2010, 28, 1554-1559. [CrossRef] [PubMed]

24. Du, J.; Xing, Q.; Xu, L.; Xu, M.; Shu, A.; Shi, Y.; Yu, L.; Zhang, A.; Wang, L.; Wang, H.; et al. Systematic screening for polymorphisms in the CYP3A4 gene in the Chinese population. Pharmacogenomics 2006, 7, 831-841. [CrossRef] [PubMed]

25. Lane, S.; AI-Zubiedi, S.; Hatch, E.; Matthews, I.; Jorgensen, A.L.; Deloukas, P.; Daly, A.K.; Park, B.K.; Aarons, L.; Ogungbenro, K.; et al. The population pharmacokinetics of R- and S-warfarin: Effect of genetic and clinical factors. Br. J. Clin. Pharmacol. 2012, 73, 66-76. [CrossRef] [PubMed]

26. Du, J.; Zhang, A.; Wang, L.; Xuan, J.; Yu, L.; Chen, R.; Li, X.; Gu, N.; Lin, Z.; Feng, G.; et al. Relationship between response to risperidone, plasma concentrations of risperidone and CYP3A4 polymorphisms in schizophrenia patients. J. Psychopharmacol. 2010, 24, 1115-1120. [CrossRef] [PubMed]

27. Ren, Z.Y.; Xu, X.Q.; Bao, Y.P.; He, J.; Shi, L.; Deng, J.H.; Gao, X.J.; Tang, H.L.; Wang, Y.M.; Lu, L. The impact of genetic variation on sensitivity to opioid analgesics in patients with postoperative pain: A systematic review and meta-analysis. Pain Physician 2015, 18, 131-152. [PubMed]

28. Zheng, Q.; Wu, H.; Yu, Q.; Kim, D.H.; Lipton, J.H.; Angelini, S.; Soverini, S.; Vivona, D.; Takahashi, N.; Cao, J. ABCB1 polymorphisms predict imatinib response in chronic myeloid leukemia patients: A systematic review and meta-analysis. Pharmacogenom. J. 2015, 15, 127-134. [CrossRef] [PubMed]

29. Hoffmeyer, S.; Burk, O.; von Richter, O.; Arnold, H.P.; Brockmöller, J.; Johne, A.; Cascorbi, I.; Gerloff, T.; Roots, I.; Eichelbaum, M.; et al. Functional polymorphisms of the human multidrug-resistance gene: Multiple sequence variations and correlation of one allele with P-glycoprotein expression and activity in vivo. Proc. Natl. Acad. Sci. USA 2000, 97, 3473-3478. [CrossRef] [PubMed]

30. Breedveld, P.; Pluim, D.; Cipriani, G.; Wielinga, P.; van Tellingen, O.; Schinkel, A.H.; Schellens, J.H. The effect of Bcrp1 (Abcg2) on the in vivo pharmacokinetics and brain penetration of imatinib mesylate (Gleevec): Implications for the use of breast cancer resistance protein and P-glycoprotein inhibitors to enable the brain penetration of imatinib in patients. Cancer Res. 2005, 65, 2577-2582. [PubMed]

31. Oostendorp, R.L.; Buckle, T.; Beijnen, J.H.; van Tellingen, O.; Schellens, J.H. The effect of P-gp (Mdr1a/1b), BCRP (Bcrp1) and P-gp/BCRP inhibitors on the in vivo absorption, distribution, metabolism and excretion of imatinib. Investig. New Drugs 2009, 27, 31-40. [CrossRef] [PubMed]

32. Choi, Y.; Jiang, F.; An, H.; Park, H.J.; Choi, J.H.; Lee, H. A pharmacogenomic study on the pharmacokinetics of tacrolimus in healthy subjects using the DMETTM Plus platform. Pharmacogenom. J. 2016. [CrossRef]

33. Zhang, J.; Kuehl, P.; Green, E.D.; Touchman, J.W.; Watkins, P.B.; Daly, A.; Hall, S.D.; Maurel, P.; Relling, M.; Brimer, $\mathrm{C}$; et al. The human pregnane $\mathrm{X}$ receptor: Genomic structure and identification and functional characterization of natural allelic variants. Pharmacogenetics 2001, 11, 555-572. [CrossRef] [PubMed]

34. Lamba, J.; Lamba, V.; Schuetz, E. Genetic variants of PXR (NR1I2) and CAR (NR1I3) and their implications in drug metabolism and pharmacogenetics. Curr. Drug Metab. 2005, 6, 369-383. [CrossRef] [PubMed]

35. Deininger, M.W.; O'Brien, S.G.; Ford, J.M.; Druker, B.J. Practical management of patients with chronic myeloid leukemia receiving imatinib. J. Clin. Oncol. 2003, 21, 1637-1647. [CrossRef] [PubMed]

36. Guilhot, F. Indications for imatinib mesylate therapy and clinical management. Oncologist 2004, 9, $271-281$. [CrossRef] [PubMed] 
37. Trent, J.C.; Patel, S.S.; Zhang, J.; Araujo, D.M.; Plana, J.C.; Lenihan, D.J.; Fan, D.; Patel, S.R.; Benjamin, R.S.; Khakoo, A.Y. Rare incidence of congestive heart failure in gastrointestinal stromal tumor and other sarcoma patients receiving imatinib mesylate. Cancer 2010, 116, 184-192. [CrossRef] [PubMed]

38. Verweij, J.; Casali, P.G.; Zalcberg, J.; LeCesne, A.; Reichardt, P.; Blay, J.Y.; Issels, R.; van Oosterom, A.; Hogendoorn, P.C.; Van Glabbeke, M.; Bertulli, R.; et al. Progression-free survival in gastrointestinal stromal tumours with high-dose imatinib: Randomised trial. Lancet 2004, 364, 1127-1134. [CrossRef]

39. Blanke, C.D.; Rankin, C.; Demetri, G.D.; Ryan, C.W.; von Mehren, M.; Benjamin, R.S.; Raymond, A.K.; Bramwell, V.H.; Baker, L.H.; Maki, R.G.; et al. Phase III randomized, intergroup trial assessing imatinib mesylate at two dose levels in patients with unresectable or metastatic gastrointestinal stromal tumors expressing the kit receptor tyrosine kinase: S0033. J. Clin. Oncol. 2008, 26, 626-632. [CrossRef] [PubMed]

40. Thanopoulou, E.; Judson, I. The safety profile of imatinib in CML and GIST: Long-term considerations. Arch. Toxicol. 2012, 86, 1-12. [CrossRef] [PubMed]

41. Oostendorp, R.L.; Beijnen, J.H.; Schellens, J.H.; Tellingen, O.V. Determination of imatinib mesylate and its main metabolite (CGP74588) in human plasma and murine specimens by ion-pairing reversed-phase high-performance liquid chromatography. Biomed. Chromatogr. 2007, 21, 747-754. [CrossRef] [PubMed]

42. Loparev, V.N.; Cartas, M.A.; Monken, C.E.; Velpandi, A.; Srinivasan, A. An efficient and simple method of DNA extraction from whole blood and cell lines to identify infectious agents. J. Virol. Methods 1991, 34, 105-112. [CrossRef]

43. Shi, Y.Y.; He, L. SHEsis, a powerful software platform for analyses of linkage disequilibrium, haplotype construction, and genetic association at polymorphism loci. Cell Res. 2005, 15, 97-98. [CrossRef] [PubMed]

(C) 2017 by the authors. Licensee MDPI, Basel, Switzerland. This article is an open access article distributed under the terms and conditions of the Creative Commons Attribution (CC BY) license (http:/ / creativecommons.org/licenses/by/4.0/). 